\title{
Effectiveness of integration transactions of companies in the environmental sector
}

\author{
Igor Aleksandrov ${ }^{1, *}$, Marina Fedorova ${ }^{2}$, and Aleksey Parshukov ${ }^{1}$ \\ ${ }^{1}$ Peter the Great St.Petersburg Polytechnic University, Polytechnicheskaya 29, 195251, St. \\ Petersburg, Russia \\ ${ }^{2}$ Petrozavodsk State University, Lenina 33, 185910, Petrozavodsk, Russia
}

\begin{abstract}
This article is aimed at improving the processes of evaluation by enterprises of the agro-industrial complex of planned decisions on acquisitions and mergers. The work is based on the analysis of integration evaluation problems, known approaches to their solution, and the development of the conceptual framework for evaluating these transactions. The article offers a method developed by the authors to assess the effectiveness of merger processes. The proposed method for evaluating mergers is developed on the basis of assessing the change in the company's potential after the merger. The assessment of potential changes resulting from the implementation of integration projects will allow assessing the economic impact of merger options, taking into account the environmental consequences for the territory. The proposed method is aimed at more accurate accounting of changes in the intangible assets of the combined company as a result of integration. Rationalizing the evaluation of the effectiveness of mergers will allow the owners of the evaluated companies to improve the quality of preparation of integration transactions and reduce the risks of making inefficient decisions.
\end{abstract}

\section{Introduction}

The relevance of the study is determined by the strategic nature, high significance of decisions on mergers and acquisitions of economic entities and the wide scale of integration processes at present time in Russia.

The Russian economy has a number of systemic problems that make obstacles for the country to take a well-deserved share in total world production. Russian agriculture has a significant potential and can become a source of development of vast territories of Russia $[1]$.

The crisis phenomena of recent years have made it difficult for Russian companies to use relatively easily accessible and cheap foreign debt capital [2]. Many announced investment projects have been suspended or cancelled due to general uncertainty.

At present, mergers are often the only way to raise funds to refinance or support planned projects. In recent years, the number of mergers and acquisitions in Russia has been

\footnotetext{
*Corresponding author: a7830298@gmail.com
} 
constantly growing. This study is aimed at improving the efficiency of evaluating mergers for companies in the agro-industrial complex.

\section{Literature Review}

Successful management of the company implies the ability to respond quickly to possible changes in the economic, political, legal and social factors of the external environment [3]. Mergers and acquisitions of economic entities are one of the forms of reorganization as a response to these changes. Mergers of companies are an integral part of the life cycle, so these transactions remain an essential part of the modern economy and are an important element of market regulation [4].

It should be noted that the main motive driving managers and owners to make decisions on mergers and acquisitions is the possibility of a synergistic effect, which means that the result of the merger exceeds the results of the companies participating in the merger, and the result of the acquisition exceeds the transaction price [5].

Mergers is an important element of the company's strategic management, which is carried out in the interests of increasing its potential and ensuring its strategic invulnerability [6].

Strategic potential is assessed by analyzing the internal and external environment. As a result, an assessment is made within the framework of the set goal: how much the enterprise meets the target requirements in terms of the quantity and quality of resources, the state of functions and projects [7]. The analysis clarifies the strengths and weaknesses of the enterprise [8]. Strengths are possible key success factors.

Practice shows that most transactions related to mergers are unsuccessful for the companies that initiate them [9].

The purpose of any merger is to make a profit, return on investment, but not the fact of establishing control over a large company [10]. Typically, an analysis of the effectiveness of integration begins with a forecast of the future cash flows of the companies involved in the integration.

This forecast includes any assumption of increased revenue or reduced costs resulting from a merger or acquisition, then these amounts are discounted, and the results are compared with the transaction price.

Thus, to analyze the effectiveness of a merger of companies, it is necessary to:

- forecast cash flow forecasting;

- determine the level of the discount rate to estimate the projected cash flow;

- evaluate the shares of different shareholders in the merged company.

The approach discussed above does not always give objective results. even an experienced analyst can make serious mistakes in assessing the value of the company [11]. The expected net benefit may be positive only because of an overly optimistic assessment of the company's future cash flows [12].

It is necessary to propose an approach to evaluate the integration transactions, the use of which will reduce the risks of error decisions.

The method proposed by the authors should be based on the analysis of the company's external environment and should allow assessing the strategic climate or strategic conditions created by the external environment. 


\section{Methodology}

The authors propose a method for evaluating the effectiveness of merger processes. The method of evaluating mergers is based on assessing the change in the company's potential after the merger.

The proposed method is aimed at more accurate accounting of changes in the intangible assets of the combined company as a result of integration.

The proposed method is based on the forecast and subsequent assessment and discounting of cash flows from a certain set of projects. As methods of collecting and processing the necessary information when applying the method, the methods of collecting and processing information used in investment design and business evaluation are partially used.

The number of information sources that can be used by experts in assessing the potential, assessing the increment of potential, evaluating the effectiveness of integration processes is not limited, as is the amount of information itself.

By the potential of an organization, we will understand its ability to generate sustainable cash flows.

In [13], to solve the problem of merger evaluation, it is necessary to construct an economic and mathematical model describing the assessment of potential changes as the result of integration.

The authors proposed to calculate the potential in value terms as the sum of the net accumulated values of the Most preferred projects and the potential residual value of the company (PRV) after the completion of the projects. The potential residual value (PRV) is calculated as the product of the value of tangible assets and the efficiency ratio of the assets. This is done for a more complete accounting of the company's intellectual capital after the completion of projects. It is proposed to identify the following groups of projects for the evaluated company:

- group M1 (active projects) - traditional projects of the company $(\mathrm{m} 11, \ldots, \mathrm{m} 1 \mathrm{w})$, implemented at the time of evaluation;

- group M2 (planned projects) -the company's projects $(\mathrm{m} 21, \ldots, \mathrm{m} 2 \mathrm{q})$ that are planned for implementation;

- group M3 (potential projects)- projects $(\mathrm{m} 31, \ldots, \mathrm{m} 3 \mathrm{~g}$ ) can be implemented by the company.

Given the above, the formula for evaluating the potential of company $\mathrm{k}$ will look like this:

$$
P^{k}=B^{k}+A_{1}^{k} * \eta * \frac{B^{k}}{A^{k}}
$$

where $P^{k}$-the company's potential; $B^{k}$ the sum of the net present values w of the company's current, q planned and g potential projects; $A^{k}$ - the value of net assets at the time of valuation; $\boldsymbol{\eta}$ - an adjustment coefficient that takes into account the preservation of the company's business profile after the end of the forecast period ( $\mathbf{O} \leq \eta \leq 1{ }_{\text {); }} A_{1}^{k}$-the discounted value of net assets at the end of the planning period (excluding cash).

Cash flows from projects in groups M1, M2, M3 are discounted at rates that take into account the cost of capital, the risk of each of the projects and possible inflation. 
Formula (1) allows you to analytically assess the company's potential in the context of market value.

To apply the proposed method to evaluating the effectiveness of mergers, experts who are directly involved in the work must have all the necessary information. in principle, you can use the formula to evaluate the effectiveness of merger processes.

\section{Research}

The authors propose to evaluate the effectiveness of the proposed merger transaction by assessing the change in the potential of the company that initiates the merger. We will call this company the base company. The company that can be attached to the base company will be called the target company.

The merger will be beneficial to the shareholders of the underlying company if the potential of the underlying company increases as a result of the transaction. To identify changes in the potential of the underlying company, you need to measure the potential of the underlying company before and after the planned merger with the target company.

Based on the potential assessment model, a model for evaluating the effectiveness of merger processes can be built.

To assess the potential of the base company, it is proposed to develop the mechanism proposed by the authors [13] for assessing the potential of the company.

When assessing the potential of the basic structure without taking over the target company, the following groups of projects are considered:

- group M1 (active projects) - traditional projects of the basic structure $(\mathrm{m} 11, \ldots, \mathrm{m} 1 \mathrm{w})$, implemented at the time of evaluation;

- M2 group (planned projects) -projects of the basic structure $(\mathrm{m} 21, \ldots, \mathrm{m} 2 \mathrm{q})$ planned for implementation;

- M3 group (potential projects)- projects $(\mathrm{m} 31, \ldots, \mathrm{m} 3 \mathrm{~g})$ possible for implementation by the basic structure.

For the combined structure (as a result of the takeover), the project groups will be as follows:

- group N1 (active projects) - traditional projects of the basic structure and company goals $(\mathrm{n} 11, \ldots, \mathrm{n} 1 \mathrm{v})$ that are planned for implementation even after the merger (with possible increase in efficiency due to synergy);

- group N2 (planned projects) - projects of the basic structure and company goals $(\mathrm{n} 21, \ldots, \mathrm{n} 2 \mathrm{p})$ that were planned before the merger and remain possible after it (with possible increase in efficiency due to synergy);

- group N3 (potential projects)- projects $(\mathrm{n} 31, \ldots, \mathrm{n} 3 \mathrm{~h})$ that can be implemented if combined.

$$
\begin{gathered}
\Delta P_{c}{ }^{k}=\left(\sum_{e=1}^{v} N P V\left(n_{1 e}\right)+\sum_{b=1}^{p} N P V\left(n_{2 b}\right)+\sum_{c=1}^{h} N P V\left(n_{3 c}\right)+\right. \\
\left.+A_{1}^{k+l} * \eta_{1} * \frac{\sum_{e=1}^{v} N P V\left(n_{1 e}\right)+\sum_{b=1}^{p} N P V\left(n_{2 b}\right)+\sum_{c=1}^{h} N P V\left(n_{3 c}\right)}{A^{k+l}}\right) * \mathrm{~d}- \\
\left.-\sum_{i=1}^{w} N P V\left(m_{1 i}\right)-\sum_{j=1}^{q} N P V\left(m_{2 j}\right)-\sum_{t=1}^{g} N P V\left(m_{3 t}\right)\right) \\
-A_{1}{ }^{k} * \eta_{2} * \frac{\sum_{i=1}^{w} N P V\left(m_{1 i}\right)+\sum_{j=1}^{q} N P V\left(m_{2 j}\right)+\sum_{t=1}^{g} N P V\left(m_{3 t}\right)}{A^{k}}
\end{gathered}
$$


where $\Delta P_{c}{ }^{k}$ - the increment of the capacity of the basic structure of the takeover of the target company; $\sum_{e=1}^{v} N P V\left(n_{1 e}\right) \sum_{b=1}^{p} N P V\left(n_{2 b}\right) \quad \sum_{c=1}^{h} N P V\left(m_{3 c}\right)$ and -the sum of the net present value of existing $\mathrm{v}, \mathrm{p}$ h planned and potential projects of the joint structure; $\sum_{i=1}^{w} N P V\left(m_{1 i}\right) \sum_{j=1}^{q} N P V\left(m_{2 j}\right) \sum_{\text {and }}^{g} N P V\left(m_{3 t}\right) \quad$ - the sum of the net present value $\mathrm{w}$ active, q g planned and potential projects of the basic structure; $A_{1}^{k+l}$ - the discounted net asset value of the combined company at the end of the planning period (excluding cash); $A^{k+l}$-the value of the net assets of the combined company at the time of evaluation; ${ }^{A_{1}^{k}}$ the discounted net asset value of the underlying structure (excluding cash) at the end of the planning period; ${ }^{k}$-the net asset value of the underlying structure at the time of valuation; $\eta_{1}$ and $\eta_{2}$-correction factors that take into account the preservation of the combined company's business profile and the underlying structure after the end of the forecast period ; d-share of shareholders of the basic structure in the combined company.

\section{Discussion}

To apply the proposed method to evaluate the effectiveness of mergers, experts who are directly involved in the work must have all the necessary information. The proposed method is based on the forecast and subsequent assessment and discounting of cash flows from a certain set of projects.

Modern markets are characterized as global, primarily due to the news information that instantly spreads to them. The information disclosed in various classifications reflects its most important properties, which must be taken into account when conducting a potential assessment [14].

It should be understood that the number of information sources that can be used by experts in assessing the potential, assessing the increment of potential, assessing the effectiveness of integration processes is not limited, as is the volume of information itself [15].

Information obtained from external sources primarily includes information provided by various information and consulting agencies, government agencies, scientific institutions, etc. Information obtained from internal sources should give the most complete picture of the companies intended to participate in the integration. In the event that the persons conducting the assessment cannot obtain this information from the management or owners, it is possible to obtain information from external sources: consulting agencies, etc. It is obvious that when working out a possible merger or acquisition option, the company that initiates the integration can not always rely on complete information about the target company. The owners of the target company can resist disclosure of data for internal use as much as possible until they are at least partially interested in negotiating a deal, for which it is necessary to offer a range of prices in the case of a takeover, and in the case of a mergerindicate its possible forms. Sometimes it is highly desirable for the initiator of the merger to keep the fact of interest secret for as long as possible, so as not to provoke an increase in the value of the target company's shares in anticipation of the transaction. 


\section{Conclusion}

The proposed method is aimed at more accurate accounting of changes in the intellectual property of the combined company as a result of the merger. The use of such a universal indicator of the effectiveness of a merger of companies as a change in potential will allow taking into account not only the economic, but also the environmental consequences for the territory from the proposed integration projects.

In order to assess the potential of an economic entity (respectively, and when assessing the increment of potential as an indicator of the effectiveness of possible integration) the intellectual capital at the end of the planning period has been estimated. it is proposed to take into account the potential residual value of the company as a component of the potential.

Assessment of potential changes as a result of implementation of integration projects will allow assessing the effectiveness of projects for the long-term development of the company's agro-industrial complex.

The proposed approach to assessing acquisitions based on the assessment of potential changes is designed to reduce the risks of revaluation of the discounted cash flow from acquisitions through a critical risk analysis of each project.

\section{References}

1. P.V. Druzhinin, A.P. Shcherbak, S.V. Tishkov, Stud. Russ. Econ. Dev. 29(3), 280-287 (2018) DOI: 10.1134/S1075700718030036

2. M.N. Mukhanova, Soc. J. 2(23), 74-95 (2017) DOI: 10.19181/socjour.2017.23.2.5161

3. E.A. Shlapeko, S.V. Stepanova, Geo. Polon. 91(3), 301-315 (2018) DOI: 10.7163/GPol.0122

4. O. Rasskazova, O. Kalinina, E. Zotova, MATEC Web of Conferences 170, 01041 (2018) DOI: https://doi.org/10.1051/matecconf/201817001041

5. V. Plotnikov, E. Gorin, O. Pirogova, E3S Web of Conferences 91, 08021 (2019) DOI https://doi.org/10.1051/e3sconf/20199108021

6. D.O. Strebkov, A. V. Shevchuk, M.O. Spirina, The Monitoring 6, 89-106 (2016) DOI: 10.14515/monitoring.2016.6.06

7. A Bril, O. Kalinina, A. Kankovskaya, V. Vilken, E3S Web Conf. 110, 02018 (2019) DOI: $10.1051 / \mathrm{e} 3$ sconf/201911002018

8. A.V. Simakova, G.B. Kozyreva, World Ec. Man. 18(1), 129-139 (2018) DOI: 10.25205/2542-0429-2018-18-1-129-139

9. S.S. Patrakova, Territorial Development Issues 8, 1-16 (2020) DOI: 10.15838/tdi.2020.1.51.1

10. M.Yu. Fedorova, The scientific journal of the State Commission for Academic Degrees and Titles «Regional problems of transforming the economy» 3, 36-43(2017) DOI:10.26726/2305-4484-2017-3-36-43

11. O.V. Petrichenko, M.A. Timofeenko, Sinnergia Nauk 19, 48-53 (2018)

12. V. Plotnikov, O. Pirogova, E3S Web of Conferences 157, 04007 (2019) DOI https://doi.org/10.1051/e3sconf/202015704007

13. I. Aleksandrov, M. Fedorova, E3S Web of Conferences 110, 02019 (2019) DOI $10.1051 / \mathrm{e} 3$ sconf/201911002019 
14. O. Rostova, S. Shirokova, N. Sokolitsyna and A. Shmeleva, E3S Web of Conf. 110, 02032 (2018) DOI:https://doi.org/10.1051/e3sconf/201911002032

15. I. Aleksandrov, M. Fedorova, Sc. J. of KubSAU 10 (2017) Doi: 10.21515/1990-4665134-063 